\title{
O FIM DO LIVRO? \\ O QUE AS ESCRITAS E OS ESCRITORES VIRTUAIS NOS AUXILIAM NESSA DISCUSSÃO NA PERSPECTIVA DA HISTÓRIA DAS PRÁTICAS DE LEITURA E ESCRITA ${ }^{1}$
}

Larissa Camacho Carvalho Universidade de Caxias do Sul (UCS)

Maria Stephanou

Universidade Federal do Rio Grande do Sul (UFRGS)

\section{RESUMO}

$\mathrm{Na}$ história das práticas de leitura e escrita os suportes que contém os textos possuem grande relevância, pois são fundamentais para a compreensão das apropriações dos textos pelos seus leitores e das possibilidades dos protocolos de leitura colocados nos textos pelos seus escritores. Como lemos envolve em que suporte o fazemos e isso modifica nossa relação com o escrito. A partir do referencial da História Cultural, este texto realiza uma análise dos suportes de escrita e leitura a partir das transformações ocasionadas pelos computadores e a internet e buscando outras revoluções nos suportes na história do livro chegando à passagem do rolo ao códex no século V d.C.

Palavras-chave: História Cultural; Suportes; História das Práticas de Leitura e Escrita; História da Educação.

\section{THE END OF THE BOOK? \\ WHAT THE WRITTEN AND WRITERS VIRTUAL HELP US IN THIS DISCUSSION FROM THE PERSPECTIVE OF THE HISTORY OF READING AND WRITING PRACTICES}

\begin{abstract}
In the history of reading and writing practices the supports that containing the texts have great relevance, as they are fundamental for understanding the appropriation of texts by readers and the possibilities of reading protocols placed in the texts by their authors. The way we read involves in which supports we do this and it changes our relationship with writing. From the framework of Cultural History, this paper makes an analysis of the supports of written and reading from the changes caused by computers and the internet and search for other revolutions in the supports of the book's history coming to the pass to roll until the codex in the fifth century AD.

Keywords: Cultural History; supports; History of Reading and Writing Practice; History of Education.
\end{abstract}




\section{Introdução}

As escritas virtuais fazem parte de uma longa história das práticas de leitura e escrita ocidentais. Por essa questão, as inovações e transformações que pensamos fazerem parte de uma era virtual, contemporânea, nada mais são que parte de um processo dinâmico da história das práticas de ler e escrever. Nesse sentido, nos deparamos, hoje, com muitas pesquisas relativas às escritas e leituras virtuais inserindo-as no estudo da história dessas práticas de leitura e escrita, percebendo suas continuidades e rupturas relativamente às práticas manuscritas e impressas dos livros, dos textos em geral, jornais e destacando as transformações que suscita buscando paralelos entre revoluções ${ }^{2}$ das práticas de leitura e escrita em tempos anteriores e na atualidade.

Pensando nessas revoluções, nas transformações das práticas de leitura e escrita da atualidade, mas também naquelas outras que ocorreram em outros períodos da história e que marcaram profundamente nossa cultura, no ano de 2012 defendi tese de doutorado em Educação que investigou uma prática de escrita virtual de jovens, bastante difundida na internet, que, embora nova em seus suportes, faz parte de um longo processo histórico de práticas de escrita protagonizadas por leitores que lêem outros autores.

Essas práticas produzem textos que denominam-se fanfictions que podem ser definidas como textos escritos por fãs de uma obra original. A expressão obra original designa um livro, uma série de livros, um filme, um mangá (história em quadrinhos japoneses), um animê (desenho animado japonês), uma série televisiva, uma história em quadrinhos, um desenho animado, um jogo para computador ou vídeo game e mesmo uma banda musical, criados ou escritos originalmente, ou seja, sem lançarem mão de personagens já existentes, universos ficcionais anteriormente utilizados em outras obras do mesmo gênero ou em outros gêneros de obras, ou sem se apresentarem como continuidades de histórias previamente existentes. Da mesma forma, autor original designa os criadores dessas obras originais.

As fanfictions constituem-se em histórias ficcionais criadas por fãs dessas obras originais. Os fãs se valem dos cenários, dos personagens, do universo, da história em si destas obras para modificarem partes do enredo ou seu final, ou então para continuarem as tramas, dar visibilidade a um personagem coadjuvante, inserir novos personagens em interação com os personagens originais, entre outras possibilidades de criação a partir do universo apreciado. Os sujeitos que escrevem estas histórias são denominados ficwriters.

\section{Caminhos da Pesquisa}

Para dar conta de compreender as práticas de escritas de fanfictions a pesquisa utilizou-se da netnografia que, segundo Fragoso, Recuero e Amaral seria uma transposição do método etnográfico em relação à internet (Fragoso; Recuero; Amaral, 2011:168). Assim, a netnografia possui relação intrínseca com a etnografia, tendo peculiaridades relativas ao lócus de estudo que não se constitui mais como uma comunidade limitada a um espaço geográfico, mas comunidades, grupos, movimentos que se organizam num espaço virtual. Embora a netnografia tenha sido realizada em quatro diferentes sites especializados (FanFiction.net, Floreios e Borrões ${ }^{3}$ (FeB), Nyah! Fanfiction ${ }^{4}$ e AnimeSpirit Fanfics $^{5}$ ), a pesquisa empírica centrou-se no site FanFiction.net.

Em todas as páginas da internet escolhidas para a observação netnográfica foi necessário uma entrada em campo na condição de usuária. Para ter acesso aos ficwriters era necessário inscrever-se nos sites como qualquer sujeito que almeje postar fanfics. Assim, também criei e mantive contas nos sites observados. Foi o modo encontrado para 
ter contato com o grupo o qual eu desejava observar. Tratando-se ainda das preliminares da netnografia, Fragoso, Recuero e Amaral observam que: “(...) o processo de construção da etnografia consiste em saber ver, saber estar com e saber escrever. Os atos descritivos incluem uma série de protocolos a serem devidamente organizados" (FRAGOSO; RECUERO; AMARAL, 2011:185). Foi necessário saber ver. Para ver melhor, foi preciso a inscrição nos sites especializados em postagens de fanfics. Mas como estar nesses ambientes virtuais? Optei por inserir-me como pesquisadora "silenciosa" ou "lurker" que, segundo Fragoso, Recuero e Amaral, em nota de rodapé, é o pesquisador que pratica o lurking: "ato de entrar em lista de discussão, fóruns, comunidades online etc. apenas como observador, sem participação ativa" (FRAGOSO; RECUERO; AMARAL, 2011:192).

A partir dessa metodologia advinda da netnografia foram produzidos um total de duzentas e quarenta e sete (247) páginas da internet, observadas e gravadas as imagens enquanto documentos de pesquisa. Além destes, foram enviados convites de participação para ficwriters responderem a um questionário formulado com o intuito de produzir outros documentos de análise da pesquisa. O envio foi realizado através do site FanFiction.net (quarenta convites enviados), dez (10) através do site Nyah! Fanfiction e vinte (20) através do site FictionPress ${ }^{6}$. Salienta-se que todos os sujeitos que responderam ao questionário e que foram abordados pelo site FictionPress eram ficwriters, em geral também com perfil no FF.

Dos 70 (setenta) questionários enviados, foram obtidas vinte e seis (26) respostas. Destes 26 questionários respondidos acrescidos às duzentas e quarenta e sete (247) páginas da internet foi composto o corpus documental da pesquisa que ora apresento um recorte. Este, refere-se às mudanças pelas quais passou os suportes dos textos, principalmente a partir de um olhar literário, ou seja, com o auxílio de um texto de Machado de Assis em que ele escreve como a imprensa, em seu formato jornal, revolucionou os modos de comunicação permitindo diálogos entre escritores e leitores e destes últimos entre si ou entre os primeiros, o que não ocorria antes com o livro, o presente texto analisa como o suporte computador e, com ele, a internet, revolucionou os meios de comunicação na atualidade. Busca compreender quais características salientadas por Machado de Assis falam dessa revolução e se podemos compreender a atualidade dentro dessas transformações possibilitadas pela criação da prensa no século XV e que tem continuidade em nossos dias.

A questão central deste texto não é o livro, nem as práticas de leitura, mas as práticas de escrita e, particularmente, os seus suportes e como estes últimos transformamse e são capazes de gerar discussões palpitantes em defesa de cada um dos diferentes materiais e meios de conter um escrito. O livro de papel irá acabar? O jornal impresso está em extinção? Desde Machado nos fazemos estas perguntas. 


\section{Os suportes dos textos}

Machado de Assis, num texto intitulado $O$ Jornal $e$ o Livro, publicado originalmente no Correio Mercantil da cidade do Rio de Janeiro em 10 e 12 de janeiro de 1859, escreve sobre os progressos da humanidade a partir das evoluções atingidas por ela ao longo dos séculos por meio da busca dos melhores meios de propagação e perpetuação das ideias. Ele inicia com a arquitetura, considerando-a uma pedra levantada de forma conveniente, como o símbolo da representação de um pensamento. Ela tem seu desenvolvimento passando pelo Egito, Grécia e Roma e culmina com as catedrais da Idade Média. Após isso, era necessário um gigante, nas palavras do próprio Machado de Assis, para fazer morrer outro gigante e veio a imprensa, o livro ${ }^{7}$ :

O que era a imprensa? Era o fogo do céu que um novo Prometeu roubara, e que vinha animar a estátua de longos anos. Era a faísca elétrica da inteligência que vinha unir a raça aniquilada à geração vivente por um meio melhor, indestrutível, móbil, mais eloqüente, mais vivo, mais próprio a penetrar arraiais de imortalidade.

O que era o livro? Era a fórmula da nova idéia, do novo sistema. O edifício, manifestando uma idéia, não passava de uma coisa local, estreita. O vivo procurava-o para ler a idéia do morto; o livro, pelo contrário, vem trazer à raça existente o pensamento da raça aniquilada. $\mathrm{O}$ progresso aqui é evidente. (ASSIS, 1994, versão eletrônica)

E Machado de Assis completa seu argumento questionando se o livro era passível de preencher as condições do pensamento humano. E responde que sim, mas que faltava alguma coisa, pois o livro ainda não estava apto a tornar-se universal, não era "a mesa popular para a distribuição do pão eucarístico da publicidade" (Ibidem). O jornal viria preencher essa lacuna. Representou a evolução dos meios de propagação do pensamento, uma verdadeira revolução literária, social e econômica, pela capacidade de transmitir as ideias em sua efervescência e admitir debates. Todos os dias é possível levar ao jornal o que se discute nas ruas sobre os assuntos palpitantes do momento, pois ele é acessível, para leitura e para a escrita, por um maior número de pessoas. Machado de Assis acrescentava: é democrático, permitindo a todos manifestarem sua opinião em suas páginas, diferindo do livro que é moroso em sua circulação e não incita ao diálogo, também porque o jornal traz as discussões, as novidades e as mudanças ocorridas no mercado fazendo que as discussões econômicas sejam acessíveis por todos, movimentando a própria economia.

$\mathrm{Na}$ época do apogeu da imprensa, Machado vê nesse meio de propagação e perpetuação das ideias uma verdadeira revolução para a sociedade e uma evolução dos meios. O que diria ele do computador e da internet? Não há como saber. Mas pelas palavras do autor, seguindo as trilhas de seu pensamento, podemos perceber sua compreensão da evolução dos suportes dos textos, ou melhor, da impressão dos pensamentos ao longo dos tempos. Uma catedral não é passível de leitura, não contém um texto, mas representa as ideias daqueles que a construíram a seu tempo, possui a marca desse próprio tempo, diz às novas gerações algo do que quiseram simbolizar e as ideias que foram aniquiladas, embora as novas gerações possam perceber esses símbolos de acordo com as categorias próprias de seu tempo e diferentes gerações futuras farão leituras diversas sobre as mesmas representações simbólicas que, também, já não serão as mesmas pela própria ação do tempo que as deforma e reforma a paisagem ao redor.

Os livros e os jornais são passíveis de leitura. São objetos dados a ler, contém um texto, o suportam e, portanto, eles são a representação, para além do símbolo, das gerações 
precedentes; eles dão voz a essas gerações. Mas não deixam de ser transmitidos conforme os tempos, os lugares e os sujeitos que os leem. A leitura de um jornal lido no dia em que saiu impresso não é a mesma leitura desse mesmo jornal lido no dia posterior, por outro sujeito leitor. A leitura de um livro de Vitor Hugo lido no século XIX na França não será a mesma realizada, do mesmo livro, do mesmo autor, lido no século XXI por um leitor/escritor de fanfic. Mudam os sujeitos, os tempos e os lugares, mudam os suportes do texto e os sentidos atribuídos ao texto, embora supostamente este se mantenha o mesmo. Será? O fato de poder ser lido em diferentes momentos da história, de suas páginas conterem um dos mais fidedignos sistemas simbólicos de representação do pensamento que nossa humanidade criou até o momento, que são as palavras que compõem frases, parágrafos e ideias, faz com que os livros e os jornais sejam considerados uma grande evolução dos meios de propagação e perpetuação das ideias. O jornal, depois o livro, para Machado de Assis, simboliza a evolução dos suportes.

$\mathrm{Na}$ visão do consagrado intelectual brasileiro, o suporte jornal avança pelo fato de ser democrático. Uma opinião de um indivíduo remetida a um periódico para publicação, e após publicada, pode ser rebatida ou apenas discutida por leitores que leram a opinião num dia e, imediatamente, decidiram que deveriam emitir, também, sua opinião. O livro, anterior ao jornal, não permite esse debate ocorrido no calor dos acontecimentos. Um autor escreve seu livro literário, filosófico, científico e somente receberá opiniões, sugestões, reclamações de leitores após um longo período, que inclui o encaminhamento do livro à editora, ao impressor, às livrarias, para então chegar até as mãos dos leitores que, após lêlo todo, poderão ou não decidir por escrever uma carta ao autor que, provavelmente, será enviada à editora que avaliará e a remeterá ao autor. O jornal, por sua vez, embora a rapidez com que forneça as informações aos leitores e desses aos periodistas e articulistas, não é isento dessas mediações citadas acima para o caso dos livros.

E o computador? E as possibilidades oferecidas pela internet? Fazem parte desse processo evolutivo ou são sua degenerescência?

Machado questionou se o jornal mataria o livro ou o livro absorveria o jornal. Nem um, nem outro. A tiragem de livros, na atualidade, alcança números expressivos. Em 2009, o livro O Símbolo Perdido, do autor norte-americano Dan Brown, chegou ao Brasil com uma tiragem inicial de 800 mil cópias e o maior sucesso do autor, $O$ Código da Vinci, vendeu, só no país, 1,6 milhões de exemplares até esta data (COZER, 2009). De outra parte, o jornal, incluindo as versões eletrônicas, continua possuindo uma função social bastante importante em nossa sociedade.

Retorno à pergunta: E o computador? Como o mais novo suporte de texto, e a internet que está a ele associada na atualidade, estão modificando os suportes que os antecederam? Tais suportes não estão passando imunes à era tecnológica. As versões eletrônicas dos periódicos estão tomando o lugar de destaque na propagação desse veículo de informação que é o jornal. Grandes redes de jornais impressos como O Globo ${ }^{8}$, Zero Hora $^{9}$, A Gazeta ${ }^{10}$ possuem suas versões digitais que requerem assinaturas e têm periodicidade diária. Os e-books, ou eletronics books, ou livros eletrônicos, estão conquistando leitores no nosso país e em inúmeros outros. O suporte destes livros e periódicos eletrônicos é o mesmo: o computador, o objeto que contém o texto não se diferencia em sua materialidade, é sempre o mesmo, ou melhor, há variados modelos - de mesa, portáteis, miniaturizados - diferentes modelos portadores das mesmas funções enquanto suportes de textos. Podemos comparar isso ao códex e seus diferentes formatos como in-8, in-12, in-fólio. 
Por isso, a discussão atual entre os pesquisadores da área tem como mote o questionamento expresso na indagação: o computador acabará com o livro ou será uma moda passageira incapaz de substituir a função ocupada pelo objeto livro em nossa sociedade ocidental? Umberto Eco, já em 1996, num texto intitulado Da internet a Gutemberg, aposta que não, e traz à tona alguns exemplos que justificam sua resposta. $\mathrm{O}$ texto de Platão, na obra Fedro, por exemplo, quando o inventor da escrita apresenta sua invenção a um faraó que não se satisfaz com a ideia, pois ela não mais permitirá que as pessoas treinem a memória. Alguns séculos depois, na obra $O$ corcunda de Notre-Dame, de Vitor Hugo, cuja história se passa pouco tempo depois da invenção da imprensa, o personagem do padre Claude Frollo, aponta para o livro e depois para a catedral e diz que aquele matará essa (ECO, 1996).

$\mathrm{O}$ medo de que as inovações que surgem acabem por destruir aquilo que foi conquistado, não é somente do nosso tempo. Dizia-se, popularmente, que a televisão substituiria o rádio e este persiste sendo um dos principais veículos de informação, juntamente com a televisão. Diz-se, hoje, que a internet substituirá a televisão, o rádio, os livros, os tocadores de DVDs e CDs, os jornais, até mesmo a sala de aula e os professores. A rapidez com que essas mudanças foram implantadas na nossa sociedade não nos faz perceber, muitas vezes, que elas fazem parte dessa história de longa duração, que passa pelos desenhos, imagens, monumentos, e que chega à escrita, incrustada na pedra, na madeira, no papiro como rolo, no papel, faz surgir o livro, difunde a escrita e o livro pela impressão, assiste ao nascimento dos periódicos, panfletos, difunde-se ainda mais a partir da expansão marítima, chega a outros continentes, descobre suportes semelhantes na Ásia, acompanha o surgimento da máquina de escrever. Em seguida, depara-se com a criação do computador e sua posterior miniaturização, difusão, presença em todos os ambientes sociais, até se tornar pessoal, um para cada indivíduo, portável, universal.

Retornando à questão da sobrevivência do livro e do jornal, podemos perceber que eles adaptam-se ao computador, mas os suportes impressos dos livros e dos periódicos que ainda conhecemos hoje, resistirão ao suporte computador e, também ao meio de propagação internet?

Desde o século II da era cristã, aproximadamente, vemos o rolo, ou volumem, utilizado para a escrita e lido no sentido horizontal ser substituído pelo códex, por folhas de papiros dobradas quantas vezes fosse necessário para ajustarem-se ao tamanho desejado (in-fólios, in-quartos, in-octavos), obtendo o formato de cadernos. Os livros, assim, possuíam o número de cadernos que seu volume necessitava.

O códex possibilitou a independência do leitor frente ao texto e do escritor perante a pena, pois com o rolo era necessário desenvolver as ideias com o auxílio de um escriba ou secretário para anotar as reflexões que suscitavam ao autor enquanto este lia outro rolo ou apenas pensava naquilo que seria ditado. Mas somente poderiam ser lidos um de cada vez e a escrita neste suporte podia ocorrer tão somente com o apoio de uma mesa, uma base firme. Não era possível retornar com facilidade a um ponto anterior do texto após fechado o rolo. Se lido em pé, o rolo deveria ser segurando com ambas as mãos, ou era lido sentado, com o corpo imobilizado para ler o texto no suporte horizontal sem muito manuseá-lo.

Modificaram-se todas essas práticas com o advento do códex. O leitor e o escritor ganharam independência perante o livro. Pode-se, no formato códex, segurar o livro com apenas uma das mãos, se o tamanho permitir. Com o sistema de paginação das folhas do livro pode-se marcar onde uma leitura foi interrompida. Também é possível escrever no verso ou nas margens das páginas, as marginálias, aproveitar o espaço do códex para 
escrever mais, registrar idéias pessoais ou remissão a outros textos. Surgem as referências, talvez, como as conhecemos. Quando o escritor quer fazer referência a alguma parte específica de um texto de outro autor, pode fazê-lo fornecendo o nome da obra e o número da página onde se encontra a referência, algo impensado com o volumen. O leitor pode ter diante de si vários livros marcados com leituras inacabadas. Além disso, pode escrever de forma mais confortável, com uma das mãos apenas, sem ter que segurar o rolo com a outra mão enquanto escreve. Por todas essas transformações, fica claro que a passagem dos livros do formato volumen para o formato códex possibilitou uma das maiores revoluções nas práticas de leitura e escrita experimentadas até então.

Segundo Chartier, essa revolução na história do livro é apenas comparável à revolução do texto eletrônico na atualidade. Podemos dizer isto apenas, por exemplo, em relação ao suporte. Embora nem todas as transformações do suporte possam ser consideradas positivas, ou ainda não possam ser, isso não anula o impacto de uma transformação de grande monta. $\mathrm{O}$ computador é uma máquina formada por uma tela e uma caixa onde estão colocados todos os componentes eletrônicos para seu funcionamento, além dos componentes periféricos, como teclado, mouse, caixas de som, câmeras digitais e microfones e etc. Também há as versões portáteis que apenas possuem uma pequena caixa, que abre e fecha, e que contém, de um lado, a tela e, de outro, os componentes eletrônicos abaixo de uma superfície onde fica o teclado e o mouse acoplados.

Nessa máquina, em seus diferentes formatos, podemos armazenar uma infinidade de livros eletrônicos, uma verdadeira biblioteca, ocupando apenas o espaço físico, material, do volume da máquina, ou seja, a gaveta de um móvel, no caso dos computadores portáteis, ou uma escrivaninha de um escritório, no caso dos computadores de mesa. Também podemos guardá-los em dispositivos de memória portáteis, como CDs, DVDs, HD externos e pendrives. Mas não apenas livros para ler. Podemos guardar nossos próprios textos escritos no mesmo suporte de leitura dos livros, textos e artigos de revistas e de jornais, histórias em quadrinhos, além de músicas e vídeos que produzimos ou copiamos para o suporte computador. O papel é um suporte de leitura e escrita. O computador agrega essas funções e mais as da imagem e do som. A potencialidade da união dessas funções num mesmo suporte nos dá a ideia de que vivemos uma revolução que aniquilará todos os outros suportes de texto, de som e imagens anteriores.

Avaliando a história de longa duração do livro, podemos arriscar dizer que essa profecia não está totalmente conforme com o que vimos até o momento. E considerando o que dizem os sujeitos que melhor mobilizam as práticas de leitura e escrita em ambiente eletrônico, podemos concluir que, como dizem Eco \& Carrière:

Das duas, uma: ou o livro permanecerá o suporte da leitura, ou existirá alguma coisa similar ao que o livro nunca deixou de ser, mesmo antes da invenção da tipografia. As variações em torno do objeto livro não modificaram sua função, nem sua sintaxe, em mais de quinhentos anos. $\mathrm{O}$ livro é como a colher, o martelo, a roda ou a tesoura. Uma vez inventados, não podem ser aprimorados. (...) O livro venceu seus desafios e não vemos como, para o mesmo uso, poderíamos fazer algo melhor que o próprio livro. Talvez ele evolua em seus componentes, talvez as páginas não sejam mais de papel. Mas ele permanecerá o que é. (CARRIÈRE \& ECO, 2010, p.16-17)

Essa citação chancela as experiências de leitura vivenciadas por alguns sujeitos escritores de fanfics, e que pode surpreender os mais desavisados. Uma das entrevistadas 
afirmou peremptoriamente: “(...) eu só leio LIVROS impressos, odeio E-BOOKS” (Luana, entrevista recebida em 26/10/2011). Não se trata de uma rejeição ao suporte eletrônico de leitura, mas o fato do suporte impresso ainda ser tomado como a principal preferência. Eco salienta uma questão importante acerca da evolução do livro. As páginas podem não ser mais de papel, podemos não mais falar de impressos, mas de holográfico ou outra coisa a ser inventada futuramente, mas as características surgidas com o livro são o ápice da evolução dos suportes de leitura. Os sujeitos percebem esse ápice e, igualmente, a evolução possível: "Eu prefiro ler no papel, ou comprando os livros ou pegando emprestado de bibliotecas, mas quando não é uma opção eu baixo em pdf ou em audiolivro" (Cintia, entrevista recebida em 24/10/2011). "Até hoje, a maior parte dos meus livros são impressos (sou das antigas que gosta de tocar no livro, ficar folheando)" (Aline, entrevista recebida em 23/10/2011).

Tocar o livro, folheá-lo, ser "das antigas". Essas práticas percebidas como obsoletas, persistem assim como o prazer de continuar realizando-as, mesmo entre os sujeitos que, para a escrita, preferem utilizar diretamente o computador, como ocorre com a maioria dos escritores de fanfics entrevistados. Essa percepção da obsolescência do ato de folhear páginas deriva da percepção das evoluções que o suporte livro vem passando. No mundo digital,

O texto continua subsistindo, mas a página furtou-se. A página, isto é, o pagus latino, esse campo, esse território cercado pelo branco das margens, lavrado de linhas e semeado de letras e de caracteres pelo autor; a página, ainda carregada da argila mesopotâmica, aderindo sempre à terra do neolítico, essa página muito antiga se apaga lentamente sob a inundação informacional, seus signos soltos vão juntar-se à torrente digital. (LÉVY, 1996, p.48-49)

Faltam folhas para folhear; essa percepção se perde com o texto eletrônico. Também a possibilidade de escrever nas margens brancas. Elas até continuam a existir, pois é o leitor e o escritor que escolhem o formato da página que querem ler ou na qual querem escrever, mas elas não são físicas. Não é possível simplesmente apropriar-se delas, tomá-las, embora isso possa ser modificado com a invenção de novos programas de edição e leitura de textos. Ainda assim, será necessário escolher qual das margens riscadas, apropriadas, queremos acessar, pois o suporte eletrônico não permite que tenhamos todas as margens materialmente disponíveis para acesso, enfeixadas num suporte único, que transporta unicamente um texto ou conjunto de textos, mas que difere radicalmente de outros suportes, de outros livros com margens amareladas, em folha reciclável ou folha de papel couchê.

Minimizando o impacto das transformações do suporte códex para o computador com o texto eletrônico, temos como exemplo, no momento presente, os tablets e também os e-readers como o kindle, especificamente voltados para armazenarem e lerem livros com muitas funcionalidades que buscam reproduzir aquelas das folhas finas em nossas mãos. Conceito antigo, dos anos 60, que agora chega ao mercado consumidor. Eles são computadores ultraportáteis, finos, semelhantes a pranchetas, com tela sensível ao toque, que dispensam o uso de teclados e mouses. Possuem grande capacidade de armazenamento, portanto podem transportar grande quantidade de textos e livros eletrônicos. A praticidade dessa tecnologia para os leitores é enorme. Se há a necessidade de uma viagem e há obrigação de levar livros de estudo ou entretenimento, basta colocálos todos, eletrônicos, no tablet e carregá-los dentro de uma pequena bolsa, ou até mesmo num bolso grande de casaco. No trajeto de um indivíduo de casa para o trabalho ele pode 
escolher que obra lerá dentre milhares contidas em seu tablet ou no kindle, carregado na mochila. Como fazer isso com os livros impressos? Os tablets e kindle possibilitam, ainda, assinalar partes importantes do texto lido, acrescentar comentários a alguma de suas partes, marcar a leitura de um livro num ponto e passar para outro ponto, como faríamos num livro com folhas de papel.

Mas nem tudo é possível. O gesto simples de folhear o livro, por exemplo, não é a mesma coisa. Mesmo que os tablets permitam que tenhamos a sensação de folhear quando tocamos em uma das margens e a imagem de uma aba salte da tela, essa experiência não é a mesma de molhar os dedos com saliva e virar uma página. Com o livro impresso, visualmente sabemos quantas páginas faltam para serem lidas a fim de finalizarmos a leitura.

Diante do e-book sabemos, em números, a extensão das páginas faltantes, mas não temos ideia de volume, a não ser aquele gravado em nossa memória que nos permite a experiência com o impresso. Quando acrescentamos um comentário no livro eletrônico, temos que respeitar alguns passos de formatação, ou seja, clicar em botões, acessar um teclado virtual, salvar as informações anotadas. Ao escrever nas margens de nossos livros de papel, basta o lápis, nossa letra ficará grafada até que o livro se deteriore ou algo lhe suceda. A própria questão do tempo é marcada nas páginas dos livros impressos.

Quando lemos um artigo de Machado de Assis, do século XIX, publicado num periódico da época, em formato eletrônico não o diferenciamos, materialmente, de um texto de Luis Fernando Veríssimo publicado na semana passada a da leitura em seu blog. Mas quando temos o suporte jornal do século XIX, onde foi publicado o texto de Machado, com suas folhas amareladas, as letras impressas com falhas na impressão e ajustes do corretor e necessitamos de luvas e máscaras para manuseá-las, de imediato percebemos seu valor histórico, sua raridade, pois pode, o mesmo jornal, ter sido manuseado por políticos influentes de nossa história ou pelo próprio autor do texto, ou apenas porque é fruto de um tempo passado que se faz materialmente presente. Impõe sua persistência temporal. Não teremos dificuldade para diferenciar este jornal do texto escrito no blog do Veríssimo. Eletronicamente, o passado e o presente se misturam, como nos alerta Carlo Ginzburg, "Porque, no presente eletrônico, o passado se dissolve. Essa contradição já está modificando o mundo em que vivemos e em que as gerações futuras viverão. Os conceitos de presente e futuro se tornaram mais frágeis... E de passado também. Ao menos, o passado como os historiadores o viam" (GINZBURG, 2011).

Ainda sobre o tempo, a deterioração dos suportes é um elemento importante em defesa do livro impresso, como dizem Carrière \& Eco:

Os DVDs não terão vida longa. E, aliás, como dissemos, nem temos certeza de que no futuro disporemos de energia suficiente para fazer funcionar todas as nossas máquinas. Pensemos no blecaute em Nova York, em julho de 2006. Imaginemos que tivesse se estendido e prolongado, Sem eletricidade, esta tudo irremediavelmente perdido. Em contrapartida, ainda poderemos ler livros, durante o dia, ou à noite à luz de uma vela, quando toda a herança audiovisual tiver desaparecido. (CARRIÈRE \& ECO, 2010, p.30)

Não se trata de afirmar que os livros impressos sejam indestrutíveis. Eco e Carrière investem boa parte da obra citada comentando os livros antigos e raros que se desgastaram com o tempo, ou foram queimados, ou desapareceram, ou estão nas mãos de negociantes que faturam grandes lucros na especulação dos incunábulos e etc. Mas o fato é que se 
tivermos algum problema de eletricidade mundial, todos os livros, textos, sons, imagens que se encontram apenas sob o formato eletrônico, não poderão mais ser acessados, estarão fadados ao desaparecimento.

Pode parecer uma posição saudosista a que aqui está sendo apresentada, mas a intenção é ressaltar as características que fazem dos livros os suportes de leitura preferidos na atualidade, não desconhecendo que, em poucos anos, o suporte mais utilizado possam ser os netbooks, e-readers e tablets. A questão da praticidade oportunizada por estes suportes não anula as vantagens do suporte impresso e suas especificidades. E pelo número de títulos de livros que estão sendo publicados e de suas respectivas tiragens, não parece provável que em pouco tempo assistamos a substituição total do impresso pelo eletrônico. No entanto, as transformações são eminentes.

Em contrapartida, analisemos os suportes da escrita. A dupla lápis e papel deixaram de ser inseparáveis há vários anos. A máquina de escrever foi uma das primeiras a separálos e, mais recentemente, o teclado e a tela do computador substituiu-os de forma muito eficiente. Mas a dupla antes inseparável continua ativa, nas salas de aulas, em palestras, conferências, reuniões acadêmicas e profissionais para anotações, em restaurantes, lancherias e afins para tomar nota dos pedidos dos clientes, em todas as mesas de escritórios, ainda em muitos consultórios médicos, em nossas bolsas e pastas para anotar números, endereços, insights. A mobilidade do lápis ou caneta e do papel ou bloco de notas inspirou a criação dos tablets. Mas se a bateria (que tem alta durabilidade) chegar ao fim, nos restará, ainda, o lápis e o papel.

Os escritores de fanfics preferem o suporte computador para suas escritas. Utilizam cadernos, blocos e canetas quando não há um computador por perto. Aí podemos perceber a praticidade desses instrumentos de escrita milenares, que também foram evoluindo com o tempo, embora, nos mesmos termos que Eco utiliza para falar do livro, enquanto extensão do braço, não há como fazer evoluir o lápis para além de sua funcionalidade, surgida desde o princípio. Essa preferência é mais bem compreendida quando nos reportamos para o local de publicação das escritas realizadas pelos jovens, que é a internet que exige o formato eletrônico para a postagem dessas escritas.

Estes jovens igualmente escolhem o livro impresso para suas leituras, mas apenas as leituras de livros. Quando se trata de fanfics, eles leem diretamente no computador: "Para ler, prefiro ter a obra impressa. No computador, costumo ler só as fics ou matérias para trabalho, se for realmente necessário" (Iara, entrevista recebida em 23/10/2011). A não ser que queiram ler em algum outro lugar onde não haja a possibilidade de utilizar a internet ou seus computadores pessoais, então imprimem o que querem ler. Essa prática não é das mais comuns dada a efemeridade das ficções criadas por fãs. Isso também acontece com a leitura de blogs.

Assim, os textos escritos para serem publicados e circularem na internet são lidos na tela do computador. Outros escritos e impressos em folhas de papel são mais bem aceitos em sua materialidade original. Lê-se no livro impresso e na tela do computador, mas há textos específicos para uma e outra leitura. Se os sujeitos jovens, em sua maioria, que leem na tela do computador as histórias que apreciam de fãs de livros originais de literatura, preferem ler os livros dos quais são fãs em formato impresso é porque a questão dos suportes de leitura e escrita não depende exclusivamente das tecnologias disponíveis para essas práticas, mas de preferências e revoluções pertencentes a um longo histórico sociocultural que ultrapassa as fronteiras puramente tecnológicas das transformações dos suportes. 
O livro impresso tem valor diferenciado das escritas na internet, como exposto por Anabela, quando diz que tem pretensões de ser uma escritora, mas pensa que suas produções não são suficientemente boas para serem impressas, mas boas para as pessoas lerem: "Escrever fics faz parte da minha vida de forma especial, pois consigo publicar criações que não julgo boas o suficiente para, futuramente, comporem uma obra impressa, mas que são suficientemente boas para as pessoas lerem" (Anabela, entrevista recebida em 26/10/2011).

O suporte do texto representa o valor do próprio texto. Isso não significa que as fanfics sejam desvalorizadas pelos seus autores, apenas que permitem falhas, ajustes, conversas com os leitores que levarão a reajustes da escrita. A internet e, por consequência, as fanfics propiciam uma contínua reelaboração das escritas, o aniquilamento, o desaparecimento para posterior reaparecimento em novo formato, segundo a decisão de seus autores, ou a colaboração permanente dos leitores para com esses textos escritos e postados.

O livro, por sua vez, quando impresso, tem tendência à preservação, com todas as falhas, erros tipográficos ou confusões de ideias. As fanfics postadas na internet podem ser visualizadas como eternos rascunhos, prontas a serem relidas e rearranjadas a qualquer momento e a qualquer tempo. O livro impresso tem uma conotação de arte final, passível de ser corrigida, mas em edições posteriores, e não na mesma edição em que se encontram os erros.

Por fim, para não nos limitarmos à dupla triunfalismo/catastrofismo ${ }^{11}$ e tendo em conta que a invenção do livro pode ser comparada à invenção da roda - pois, uma vez descoberta, podemos aprimorá-la, mas suas funções estão todas desenvolvidas no formato em que foi criada primeiramente, ou seja, independente de ser produzida em plástico, borracha, madeira ou metal, ela persistirá com a mesma função, evoluída, é certo, mas será a roda - é necessário considerar que o suporte eletrônico de texto agrega as funcionalidades do livro, mas, também, da oralidade. E, somente com relação ao suporte, unem-se códex e volumen: a numeração de páginas, a liberação das mãos para a leitura, a possibilidade de escrever enquanto se lê e de retornar a um ponto específico em que a leitura foi interrompida, a utilização dos dois lados da folha, a possibilidade de unir vários textos num único suporte, características do códex; o rolar do texto e uma postura menos flexível do corpo (embora com os novos modelos de computadores ultraportáteis é possível ler deitado numa cama, sentado nos mais diversos e inusitados lugares, etc.) e dos próprios lugares de leitura (não é aconselhável ler dentro de uma banheira, nem é possível realizar a leitura sem energia) característicos do volumen.

Além disso, o texto eletrônico representa a superação de dois limites resistentes ao códex relativamente às práticas de escrita e leitura. Em primeiro lugar o leitor pode, agora, intervir no texto a ser lido, pode mudar completamente o escrito, apropriar-se do objeto dado a ler (e isso cria outras problemáticas) e, segundo, com o texto eletrônico há a possibilidade de concretizar-se o sonho da biblioteca universal, ou seja, a possibilidade de reunir num único lugar, no caso um espaço virtual, todos os textos, todos os escritos e, também, todos os sons, imagens, vídeos, produzidos em todos os lugares do mundo (CHARTIER, 1999a, 1999b).

Com relação à oralidade, o texto eletrônico, pela sua efemeridade e possibilidade de reescrita, ajustes, correção, aniquilamento, desaparecimento, reaparição, união de imagens, sons e palavras escritas e formas de resistir ao tempo, reproduz algumas características da oralidade, como afirma Antonio Rodríguez de Las Heras, em livro organizado por Chartier: 


\begin{abstract}
Como contrapartida, la estrategia de resistencia al paso del tiempo se aproxima más a la del texto oral que a la del texto escrito. Porque necesita la transmisión y no la preservación. El texto sobre papel necesita para permanecer la protección para que no se dañe el soporte. El texto oral está obligado a ser transmitido de unas personas a otras para que no desaparezca su memoria. De igual modo, el texto sobre soporte digital no puede mantenerse encerrado en su soporte, porque este se encuentra amenazado de obsolescencia, y la resistencia, por tanto, al paso del tiempo es poca. Así que debe renovarse mediante una migración al ritmo de los cambios técnicos.

Los dos absorben plenamente la imagen y el sonido y los mezclan con la palabra. Los dos amplifican el logro difusor de la imprenta porque son ubicuos; no necesitan copias, basta el original.

Los dos ofrecen un campo apasionante a la experimentación, en busca de nuevas formas de comunicación y de creación. Una llamada irresistible para aquellos que confían en la capacidad de la palabra (CHARTIER, 2006, p.100)
\end{abstract}

Para além disso, o texto eletrônico faz que a mensagem apareça unida ao contexto que a produziu. Envia-se uma pergunta a um fórum de discussões e obtém-se uma resposta imediata ou quase imediata. Escreve-se uma fanfic e a mesma é postada nos sítios especializados e logo os autores recebem reviews. Escreve-se num blog e seu dono pode controlar quantas pessoas e de que lugares o estão acessando em tempo real. Há programas que permitem conversações e conferências on-line com auxílio de câmeras e microfones que reproduzem a comunicação oral, mediada pelos computadores e internet. E podemos frisar e recordar que na Antiguidade a oralidade tinha, como uma de suas funções, a publicação: "(...) leer en voz alta es, para un autor, poner una obra en circulación, 'publicarla'. Esta forma (...) no será abandonada en la época moderna, entre los siglos XVI y XVIII, como forma primaria de circulación de las obras, antes de su edición impresa" (CHARTIER, 2006, p.115).

Da mesma forma, os escritores de fanfics utilizam os sites de postagem como vitrines para suas escritas, muitas vezes no intuito de tornarem-se escritores no futuro, como sinaliza Anabela quando questionada sobre o porquê escrever fanfics: "Escrever fics é um jeito de começar nesse mundo tão complicado da escrita. Dá a oportunidade para as pessoas lerem alguma coisa agradável sem pagar a mais por isso e dá a oportunidade para o escritor de saber em que precisa melhorar" (Anabela, entrevista recebida em 26/10/2011).

Não é exatamente de publicação, no sentido estrito da palavra, que estamos tratando, como a leitura oral na Idade Moderna, mas sim de circulação. Escrever fanfics e postar na internet é um meio de os escritores verem seus textos em circulação, sendo lidos por muitos sujeitos leitores, e também de eles próprios circularem na rede até que se tornem conhecidos e citados como autores preferidos de outros leitores fãs. Bianca cita autores de fanfics entre suas leituras mais marcantes: "De fics foram Maior que Tudo, Primavera, Quando for Amanhã e Santos e Assassinos , todas da Madame Verlaine, Black, da Victoria e também Anything Else, da Bel Wesley" (Bianca, entrevista recebida em 29/10/2011).

Essas possibilidades, ofertadas pela internet, de retorno à oralidade, reproduzem, em certo sentido, o contexto da comunicação face a face, um pouco diferenciada, mas sem deixar de necessitar da leitura e da escrita nesse processo. Seja para acessar os programas 
necessários às mensagens instantâneas ou às conversas online com câmera e microfone, seja para a escrita das mensagens nos correios eletrônicos, em realidade, para entrar num computador utilizamos a escrita e a leitura simultaneamente. Não há como utilizar os meios de comunicação e suportes de textos eletrônicos sem mobilizar práticas de leitura e escrita.

Pois o texto contemporâneo, alimentando correspondências on line e conferências eletrônicas, correndo em redes, fluido, desterritorializado, mergulhado no meio oceânico do ciberespaço, esse texto dinâmico reconstitui, mas de outro modo e numa escala infinitamente superior, a copresença da mensagem e de seu contexto vivo que caracteriza a comunicação oral. (LÉVY, 1996, p.39)

Mais que o fim do livro ou o texto eletrônico como uma moda, o suporte digital pode ser um retorno à palavra, ou melhor, uma revivescência do texto oral em consonância com o texto escrito, o livro e a palavra, grandes invenções da humanidade, unindo suas potencialidades. 


\section{Considerações Finais}

Nas escritas dos jovens há uma marca da revolução das práticas que é quase inseparável das fanfics: o computador. Os jovens utilizam esse suporte para a escrita de seus textos. Afirmam não ter abandonado de todo o caderno e a caneta, mas preferencialmente usam seus notebooks, celulares e ipods. A leitura de fanfics também é realizada no computador, embora os jovens deem preferência para o suporte impresso quando se trata dos livros originais. A fanfic é um texto que se dissemina virtualmente. Mas os jovens continuam utilizando as facilidades que a tecnologia do códex implantou, ou seja, a comodidade de lerem e escreverem sentados, deitados em suas camas, no refúgio de seus quartos, ou mesmo na grama do pátio da escola ou da universidade. Os desenvolvimentos tecnológicos assim o permitem. Os notebooks, depois os menores netbooks e agora os tablets (ipads) e kindle (e similares) representam os suportes do texto eletrônico em busca de uma das características dos livros que os tornam suportes ainda insubstituíveis: a mobilidade. A sobrevivência ao tempo ainda não foi superada e está longe de sê-lo. Basta acabar a eletricidade no mundo, como diz Jean-Claude Carrière (CARRIÈRE; ECO, 2010:30), e tudo estará perdido.

\section{Referências}

ASSIS, Machado de. O jornal e o livro. In.: Obra completa. Rio de Janeiro: Nova Aguilar, V.III, 1994. Disponível em http://machado.mec.gov.br/images/stories/html/cronica/macr13.htm, acesso em 30 de nov. 2011.

BRIGGS, Asa; BURKE, Peter. Uma história social da mídia: de Gutemberg à internet. $2^{\mathrm{a}}$ Ed. rev. e ampl. Rio de Janeiro: Jorge Zahar Ed., 2006.

CARRIÈRE, Jean-Claude, ECO, Umberto. Não contem com o fim do livro. Rio de Janeiro: Record, 2010.

CHARTIER, Roger. A aventura do livro: do leitor ao navegador. São Paulo: Editora UNESP/Imprensa Oficial do estado de São Paulo, 1999a.

A ordem dos livros: leitores, autores e bibliotecas na Europa entre os séculos XIV e XVIII. Tradução de Mary Del Priori. Brasília: Editora Universidade de Brasília, 1999b.

Os desafios da escrita. Tradução de Fulvia M. L. Moretto. São Paulo: Editora UNESP, 2002b.

(Org). ¿Qué es un texto? Madrid: Ediciones Ciencias Sociales, 2006.

COZER, RAQUEL. Novo livro de Dan Brown chega com tiragem recorde. Folha Online - Ilustrada. São Paulo, 21 nov. 2009. Disponível em http://www1.folha.uol.com.br/folha/ilustrada/ult90u655537.shtml, acesso em 15 de dez. 2011.

ECO, Umberto. Da internet à Gutemberg. RexLab - Laboratório de Experimentação Remota: 2003. 21 págs. (Conferência apresentada por Umberto Eco na Academia Americana para Estudos Avançados na América. 12 de novembro de 1996). Disponível em: http://www.inf.ufsc.br/ jbosco/FromInternetToGutenberg.pdf. 
FRAGOSO, Suely; RECUERO, Raquel; AMARAL, Adriana. Métodos de pesquisa para internet. Porto Alegre: Sulina, 2011.

GINZBURG, Carlo. História na era Google. Ciclo de Conferências Fronteiras do Pensamento, realizada no Salão de Atos da Universidade Federal do Rio Grande do Sul, Porto Alegre-RS, 29 de nov. 2010. (comunicação oral). Disponível em http://www.youtube.com/watch?v=wSSHNqAbd7E, acesso em 20 de dez. 2011.

LÉVY, Pierre. O que é o virtual? São Paulo: Ed. 34, 1996.

${ }^{1}$ Texto apresentado no XX Encontro da Associação Sul-Rio-Grandense de Pesquisadores em História da Educação (ASPHE), na Universidade Federal do Rio Grande do Sul (UFRGS), em dezembro de 2014, contendo parte da pesquisa de tese da autora.

${ }^{2}$ Revolução, aqui, está sendo utilizado conforme compreensão de Chartier (1999a:100-101, 2002:113).

${ }^{3}$ http://fanfic.potterish.com/

${ }^{4}$ https://www.fanfiction.com.br/

${ }^{5}$ http://animespirit.com.br/fanfics/

${ }^{6}$ Site afiliado ao Fanfiction.net dedicado às histórias originais, mas todos questionários enviados por meio deste site foram para usuários que tinham perfis no FF.

${ }^{7}$ Fica claro que Machado de Assis refere-se não ao livro manuscrito, mas à revolução provocada pela expansão do acesso aos livros pela imprensa.

${ }^{8}$ https://edigital.infoglobo.com.br/. Acessível somente com assinatura digital.

9 http://zh.clicrbs.com.br/rs/.

${ }^{10}$ http://www.gazetadigital.com.br/.

${ }^{11}$ Apropriando-me da designação dada por Briggs e Burke (2006) relativamente ao crescimento de publicações impressas no século XVII europeu, que gerava opiniões opostas entre autores preocupados com o excesso de publicações, e que tornou difícil, nas bibliotecas, encontrar um livro nas prateleiras, ou empolgados com esse excesso, semelhante à postura atual de vários autores relativamente às possibilidade propiciadas pela internet, tanto com relação à escrita como em relação à leitura e concorde com Chartier, quando refere-se ao dilema da falta e do excesso relativamente à leitura, preocupação que surge num período ainda anterior à da proliferação dos impressos no século XIX (CHARTIER, 1999a).

Recebido: maio-15 Aprovado: julho-15 